\title{
Srebrenica 20 Jahre später: Lasst uns nicht vergessen!
}

\section{Jürg Kesselring}

Prof. Dr. med., Mitglied des IKRK, Delegierter bei den Gedenkfeiern in Srebrenica am 11. Juli 2015

Es liegt ein unheimlicher, ruhiger Schrecken über Friedhöfen, auf denen alle Gräber gleich aussehen. Das Fehlen von Unterschieden bei den Grabsteinen sendet den Besuchern eine Botschaft: Etwas Furchtbares ist hier geschehen.

Man spürt dies auf dem riesigen Friedhof in Potočari bei Srebrenica, auf dem zum 20. Jahrestag an eine der düstersten Episoden des Bosnienkrieges erinnert wurde. 8000 Menschen wurden dort getötet in den heissen Sommertagen im Juli 1995. Das Internationale Komitee vom Roten Kreuz (IKRK) verlor damals neun Mitarbeiter.

In diesem Jahr fand, wie jedes Jahr, eine Zeremonie statt mit Massenbegräbnissen: Mehr als 130 Särge, bedeckt mit grünen islamischen Tüchern, wurden in den
Grund gesenkt: die letzten identifizierten Opfer eines Konfliktes, der vor so langer Zeit geendet hat.

Die meisten der Friedensstifter und Hüter des Friedens, die Journalisten und Mitarbeiter humanitärer Organisationen haben Bosnien schon längst verlassen. Andere Konflikte auf der Welt ziehen ihre Aufmerksamkeit auf sich. Aber Leichen werden hier immer noch gefunden. Über 1000 Menschen werden noch vermisst in der Gegend Srebrenica.

Jedes Jahr wird die Zahl der Opfer, die bei der Zeremonie in Potočari begraben werden, kleiner als in den vergangenen Jahren: 2012 waren es 520, 2013 409, 2014175 und in diesem Jahr 137 ... Dies ist unvermeidlich. Es ist relativ einfach, Spuren von dem zu entdecken, was mit den Vermissten geschah in den ersten Monaten und

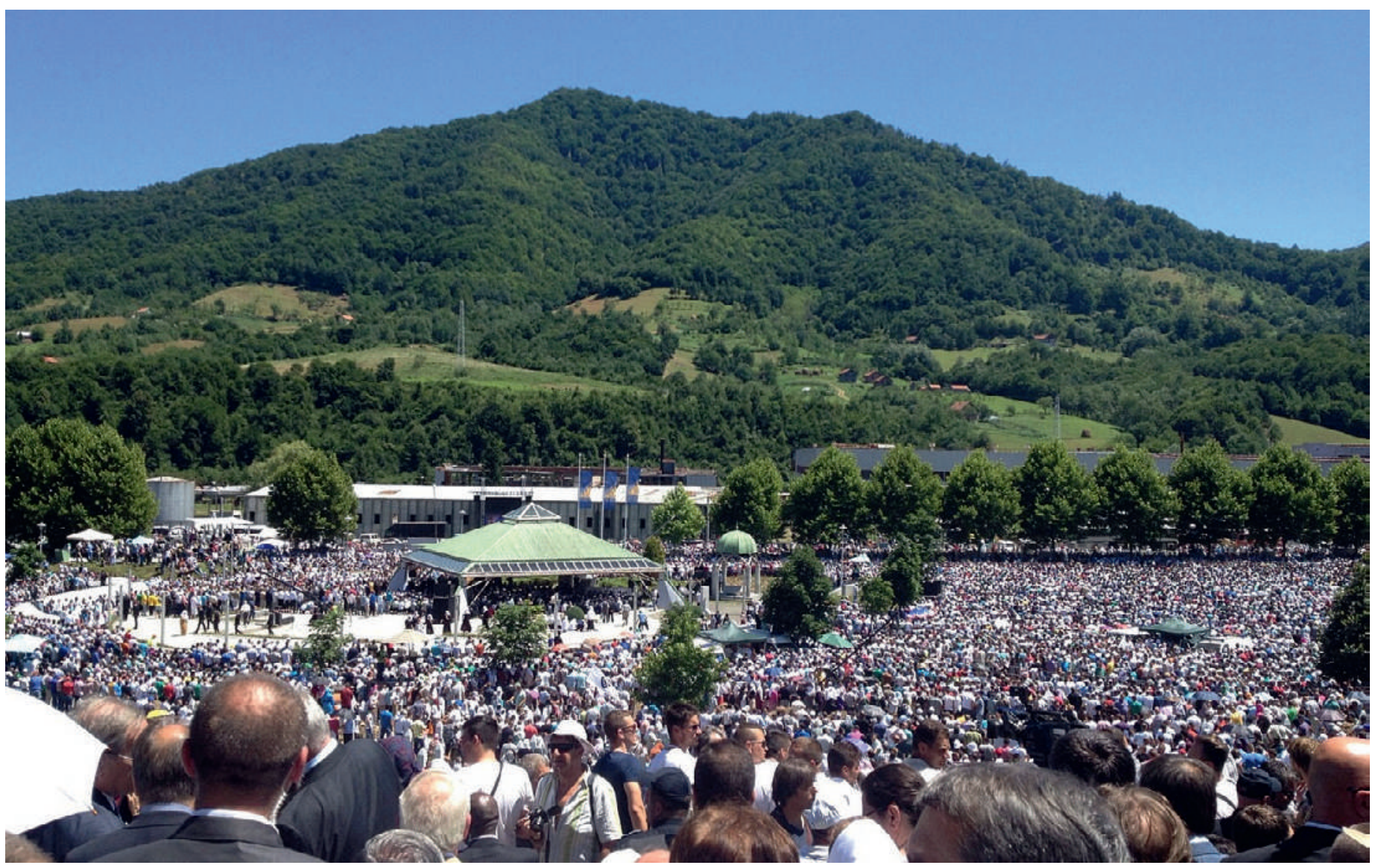

70000 nahmen teil: die Gedenkfeier in Srebrenica am 11. Juli 2015, 20 Jahre nach dem Genozid. 
Jahren nach einem Konflikt - zahlreiche Zeugen sind vorhanden und das Gedächtnis ist noch frisch. Aber diese Fortschritte können nicht gehalten werden, weil Erinnerungen verblassen, der Nachweis schwieriger zu erbringen ist. Die Vermissten vom lange zurückliegenden Konflikt können nicht konkurrieren mit denjenigen der heute brennenden Notfälle: Syrien, Irak, Jemen, Süd-Sudan. Weshalb denn ist es wichtig, dass auch heute noch die Suche nach den Vermissten von Srebrenica und des bosnischen Krieges und anderer Konflikte auf dem Balkan weitergeht?

\section{Über 1000 Menschen werden noch vermisst in der Gegend Srebrenica.}

Wir leben in einer Zeit, in der Neuigkeiten zählen, sofortiger Einfluss, unmittelbare Resultate. Sorgfältiges Durchkämmen von Archiven, genaues Anhören von Tausenden von Zeugenaussagen und das Sammeln von genetischen Informationen von Familien könnten als nostalgische und sinnlose Beschäftigung angesehen und abgetan werden.

Aber es ist wichtig, die Vergangenheit nicht zu vergessen. Die Familien haben ein Recht zu wissen, was mit jedem geliebten Angehörigen geschah. Gemeinschaften, die durch Trauer und Kummer gelähmt sind, müssen vorwärtskommen im Prozess der Versöhnung. Wir alle müssen in Frieden ruhen können.

Gut drei Viertel derjenigen, die in den Balkankonflikten der neunziger Jahre verschwunden sind, wurden mittlerweile gefunden und identifiziert. Dies ist ein gutes Ergebnis. Weit besser als in den meisten anderen Konflikten. Aber der Fortschritt ist langsam. Immer noch fehlen Spuren von vielen Vermissten in dieser Region. Das IKRK tut, was möglich ist, um in Bosnien und anderen Regionen zu helfen, so gut es eben geht. Wir unterstützen Regierungen, militärische Einrich- tungen, bewaffnete Gruppen, die unter dem humanitären Völkerrecht verpflichtet sind, Informationen zu liefern und Unterstützung zu bieten, um Familien wieder zusammenzuführen. Neben anderen Aktivitäten stellen wir unsere forensische Expertise zum Vorgang der Lokalisierung und Identifizierung der Vermissten zur Verfügung. Aber im Zentrum aller unserer Bemühungen liegen die Bedürfnisse der Familien, die nicht nur schwere psychologische Bürden, sondern auch tiefgreifende und langdauernde soziale, legale und auch ökonomische Konsequenzen zu tragen haben, wenn ihre Angehörigen verschwunden sind. In Bosnien und Herzegowina arbeiten wir mit dem Missing Persons Institute, der Rotkreuz-Gesellschaft von Bosnien und Herzegowina und anderen Institutionen zusammen - wir tun dies, weil es wichtig ist.

Es ist deshalb wichtig, weil wir in einer Welt leben, die sich stetig verändert. Wenn immer grössere Zahlen von Menschen gezwungen werden, aus ihrem Zuhause zu fliehen in Folge von Konflikten und Krisen, wenn Massengräber ausgehoben werden in den Wüsten des Mittleren Ostens, wo Tausende umkommen in ihrem Versuch, das Mittelmeer Richtung Europa zu überqueren ...

\section{Wir dürfen die Person nicht vergessen,} die einst geliebt, für die gesorgt wurde und die Hoffnungen und Träume für die Zukunft hatte.

Aber in dieser Welt von "Massen" und "Tausenden» und «Hunderttausenden» dürfen wir nicht das Individuum vergessen - weder in Srebrenica noch sonst irgendwo - nicht die Person vergessen, die einst geliebt, für die gesorgt wurde und die ihre eigenen Hoffnungen und Träume für die Zukunft hatte.

Denn wenn wir die Einzelnen vergessen, vergessen wir uns selbst. 